\title{
A Agência Nacional de Saúde e a Política de Saúde Mental no Contexto do Sistema Suplementar de Assistência à Saúde: avanços e desafios
}

\section{The Brazilian National Health Agency and the Mental Health Policy in the Context of the Private Health System: developments and challenges}

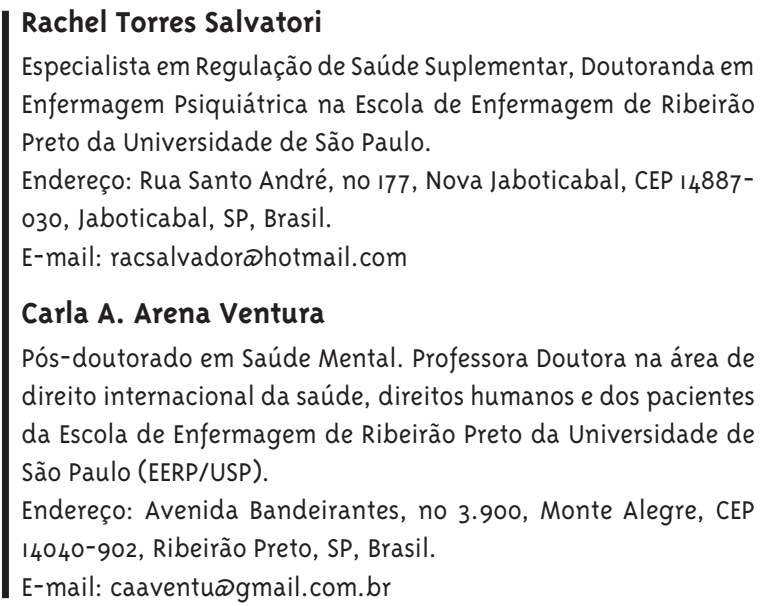

\section{Carla A. Arena Ventura}

Pós-doutorado em Saúde Mental. Professora Doutora na área de direito internacional da saúde, direitos humanos e dos pacientes da Escola de Enfermagem de Ribeirão Preto da Universidade de São Paulo (EERP/USP).

Endereço: Avenida Bandeirantes, no 3.900, Monte Alegre, CEP 14040-902, Ribeirão Preto, SP, Brasil.

E-mail: caaventu®gmail.com.br

\section{Resumo}

O presente estudo trata das políticas de saúde mental conduzidas pela Agência Nacional de Saúde Suplementar - ANS, no cenário da assistência dispensada pelos planos privados de assistência à saúde. Dessa forma, analisa o modelo de regulação econômica e assistencial do setor suplementar, a forma de atuação da ANS como organismo regulador e o tratamento dispensado à assistência à saúde mental nos normativos emanados pela Agência. Concluiu-se que, apesar de avanços como a obrigatoriedade de cobertura para todas as doenças listadas na CID-10, a inclusão do tratamento das tentativas de suicídio e das lesões autoinfligidas, o atendimento por uma equipe multiprofissional, a ampliação do número de sessões com psicólogo, com terapeuta ocupacional e de psicoterapia, e a inclusão do hospital-dia na rede credenciada da operadora, a assistência à saúde mental ainda é pouco normatizada pelos regramentos vigentes no sistema de atenção à saúde suplementar, existindo muitas lacunas a serem preenchidas. A regulamentação dos mecanismos de coparticipação e franquia, a coparticipação crescente como limitador da internação psiquiátrica sem o repensar em uma rede substitutiva e a limitação do número de sessões de psicoterapia de crise são alguns dos desafios colocados para a ANS, no sentido de que esta cumpra realmente o seu papel institucional de promoção da defesa do interesse público na assistência suplementar à saúde.

Palavras-chave: Planos de pré-pagamento em saúde; Saúde suplementar; Saúde mental; Política de saúde; Regulamentação governamental. 


\section{Abstract}

This work analyses the mental health policy-making activity of the Brazilian National Health Agency (ANS), responsible for controlling health insurance companies. Three points are discussed: a) the framework of an economic and private health assistance regulatory activity, b) the ANS and its regulation activity and c) the rules produced by ANS in the mental health care field. It was concluded that, despite advances like the legal obligation to ensure medical treatment to all the diseases listed in ICD-10, the inclusion of suicidal patient damage and self-inflicted damage care, care provided by a multiprofessional team, the increase in the number of sessions with a psychologist, with an occupational therapist and of psychotherapy sessions, and mental health day hospitals included as part of the services offered, the authors identified specific regulatory gaps in this area. Some issues that ANS has to solve so that it can really play its institutional role of defending the public interest in the private health system are: the regulation of co-participation and franchise mechanisms, the increasing co-participation as a limitation of psychiatric hospitalization, and the limited number of crisis intervention psychotherapy sessions.

Keywords: Health Insurance Plans; Private Health System; Mental Health; Health Policy; Governmental Regulation.

\section{Considerações Iniciais}

O Sistema Único de Saúde (SUS), com a consolidação da Reforma Psiquiátrica no Brasil, foi palco de transformações significativas nas políticas e ações relacionadas à saúde mental, com a ênfase na desospitalização da assistência, passando a privilegiar a criação de serviços substitutivos ao hospital psiquiátrico, que passaram a compor a Rede de Atenção à Saúde Mental: Centros de Atenção Psicossocial (CAPS), leitos psiquiátricos em hospitais gerais, oficinas terapêuticas e residências terapêuticas, respeitando-se as particularidades e necessidades de cada local (Hirdes, 2009). Essas mudanças buscam garantir ao usuário do sistema a recuperação e a manutenção de sua saúde por meio de sua reintegração à convivência social, respeitando os seus direitos como cidadãos.

Os serviços de saúde mental no Brasil podem ser públicos, quando financiados e prestados pelo Estado, e privados, quando custeados diretamente pelos indivíduos (o que pode ser chamado de sistema de desembolso direto) ou quando financiados por operadoras de planos de saúde, o que se denomina de sistema suplementar de saúde (Brasil, 20o6). Neste, o beneficiário (indivíduo que tem direito a usar este sistema privado) paga, mensalmente, uma quantia estabelecida através de contrato, a uma empresa (operadora de planos de saúde) que é responsável pela garantia da sua assistência.

Contudo, no sistema operado pelos planos de saúde, o tratamento dado à saúde mental é recente. A preocupação com essa área começou a surgir em meados de 1998, com a publicação da Resolução do Conselho de Saúde Suplementar - CONSU - nº 11, o primeiro instrumento normativo a dispor sobre a cobertura aos tratamentos de transtornos psiquiátricos no âmbito da assistência privada à saúde. Enquanto o SUS, nesse período, já estava bem avançado, o sistema suplementar de saúde caminhava lentamente, repetindo trajetos iniciais fracassados do sistema público de saúde, como a marginalização dessa área de atenção à saúde e a pouca ênfase dispensada no contexto dos instrumentos normativos do setor.

Nessa perspectiva, verifica-se que o tratamento dispensado à saúde mental nas regulamentações da saúde suplementar vigentes não só foi influen- 
ciado pelas práticas assistenciais costumeiras da época, como também influenciou a assistência à saúde mental nos períodos que se seguiram a sua publicação.

Assim, se hoje a assistência à saúde mental no âmbito do sistema privado de saúde possui uma configuração desalinhada com as políticas ministeriais, tal constatação é um produto do desenvolvimento e evolução das políticas de saúde mental capitaneadas pela Agência Nacional de Saúde Suplementar - ANS. Entretanto, deve-se ressaltar que essas políticas desenvolvidas para o setor privado são resultado da não hegemonia do modelo de reforma psiquiátrica em curso no sistema público de saúde e, principalmente, dos interesses econômicos intrínsecos ao setor privado. Tal fato demonstra que medidas urgentes precisam ser tomadas no sentido de que o setor suplementar de assistência à saúde mental acompanhe os movimentos do SUS e possa integrar-se a ele, alcançando experiências exitosas que contribuam para a melhoria das ações de saúde mental (Jardim e col., 2009).

Dessa forma, os objetivos deste artigo foram analisar as políticas de saúde mental para o setor suplementar de assistência à saúde e refletir sobre os desafios colocados para a superação do atual modelo, contribuindo para melhorias assistenciais nessa área da saúde coletiva. Para tanto, o presente estudo aborda o modelo de regulação econômica e assistencial do setor de atenção à saúde privada, descrevendo a origem e a implementação do atual modelo de Agência Reguladora. Posteriormente, são explanadas as características da ANS para que seja possível conhecer e entender a forma de atuação do órgão responsável pela formulação de diretrizes para o setor de atenção suplementar à saúde e, por último, é analisado o tratamento dispensado à saúde mental nos instrumentos normativos setoriais emanados pela ANS.

\section{Agências Reguladoras no Brasil: origem, contexto de surgimento e justificativa}

Segundo Moraes (2002), a origem das Agências Reguladoras é inglesa, através da criação pelo Parlamento, em 1834, de diversos organismos autôno- mos, com o objetivo de aplicação dos textos legais. Mais tarde, os Estados Unidos implementaram um modelo administrativo estatal baseado no modelo de agências reguladoras.

De acordo com os estudos de Ventura (2004), a base jurídica administrativa dos Estados Unidos foi estruturada, desde o seu início, através do intervencionismo indireto do Estado por meio da atuação do poder normativo, mediador e fiscalizador das agências reguladoras, com o objetivo de mediar interesses do setor, propor diretrizes públicas, tutelar e proteger interesses dos segmentos hipossuficientes.

O modelo institucional regulatório brasileiro foi fortemente influenciado pelo modelo norte-americano, com inspiração também na experiência britânica pós-privatização (Mashaw, 1997), em um formato e operacionalização que permitisse um sistema de procedimentos destinados a garantir sua transparência e a possibilidade de ampla manifestação e defesa das partes atingidas.

As Agências Reguladoras surgiram em um contexto de desestatização e de uma proposta de Reforma do Estado nos dois mandatos do presidente Fernando Henrique Cardoso (1995-2002). A privatização crescente poderia trazer prejuízos ao Estado, caso não fosse possível o monitoramento e controle das principais atividades econômicas privatizadas. Em 1995, o Plano Diretor da Reforma do Aparelho do Estado diagnosticou uma crise fiscal decorrente da perda de crédito estatal, do esgotamento da estratégia estatizante de intervenção do Estado e da forma político-burocrática da administração pública. Esses três elementos foram apontados como os principais problemas do Estado Brasileiro (Nunes e col., 2007).

Nunes e colaboradores (2007) comentam também que a proposta de reforma apresentada pelo governo sustentava-se, então, em quatro dimensões: reformas nas esferas fiscal, previdenciária, administrativa e patrimonial. A criação de um órgão independente, e não um departamento subordinado à administração direta, foi apresentada como uma inovação institucional, vinculando-se especialmente às reformas nas dimensões administrativa e patrimonial, para regular serviços públicos de energia e telecomunicações liberalizados ou privatizados de forma independente das influências político- 
partidárias dos governos.

Foi assim que, em 1996, foi criada a Agência Nacional de Energia Elétrica - ANEEL e, posteriormente, em 1997, a Agência Nacional de Telecomunicações - ANATEL, a Agência Nacional do Petróleo - ANP (no mesmo ano) e a Agência Nacional de Saúde Suplementar - ANS, em 200o, todas por meio de Leis federais.

Observa-se, nesse contexto, que a proposta da criação de um órgão com independência administrativa, financeira, patrimonial e de recursos humanos, com o modelo de agência reguladora, tinha o principal objetivo de afastar a interferência política das decisões técnicas oriundas desses órgãos, através de decisões tomadas por um colegiado de cinco diretores com mandatos fixos e não coincidentes. Segundo Ventura (2004), preservar-se-ia a estabilidade dos dirigentes, a autonomia na gestão administrativa do órgão regulador, fontes próprias de recurso e a não vinculação hierárquica da agência a qualquer instância do governo. Entretanto, deve ser salientado que a escolha desses membros da Diretoria Colegiada obedece a critérios político-partidários, o que pode comprometer profundamente o processo regulatório, com recorrentes possibilidades de captura ${ }^{1}$ do órgão regulador por parte de agentes econômicos com a exclusiva intenção de subverter os princípios do mercado a favor de interesses particulares.

Esse movimento de reforma regulatória tinha o objetivo de produzir eficiência macroeconômica pela indução e regulação da concorrência em áreas de monopólios e criar mecanismos, conforme aponta Costa (2008), para implementar políticas no contexto da pós-reforma do Estado, buscando estimular a concorrência e diminuir a regulação formal e burocrática.
Dessa forma, as Agências Reguladoras e, nesta seara, a ANS, foram instituídas para combater as falhas de mercado, como a seleção adversa ${ }^{2}$, o risco moral $^{3}$, a assimetria de informação $0^{4}$ entre agentes econômicos e as externalidades negativas ${ }^{5}$ provenientes das relações econômicas entre agentes e, por conseguinte, assegurar a competitividade de setores da economia, universalizar serviços e promover interesses dos consumidores (Peltzman, 2004; Posner, 2004).

É interessante ressaltar que, no desempenho de suas competências, as Agências Reguladoras exercem funções típicas dos três poderes. Atuam como poder executivo quando fiscalizam atividades e direitos econômicos; como poder legislativo quando publicam normas e procedimentos com força legal sobre o setor regulado e como poder judiciário, ao julgar e impor sanções aos regulados (Wald e Moraes, 1999). A atuação das Agências como quase-legislativo e quase-judiciário é criticada por especialistas da área do direito, uma vez que não atuam sob um marco regulatório adequado, que defina claramente suas atribuições, sendo configurada uma evidente invasão aos campos de atuação exclusiva de outras instituições (Wald e Moraes, 1999).

O poder normativo de uma agência reguladora é oriundo de sua atividade regulatória, uma vez que, no cumprimento legal de editar regras para o setor regulado, o faz por meio de normativos setoriais (resoluções e instruções normativas). Sobre essa situação específica, Menezello (2002), Ventura (2004) e Nunes e colaboradores (2007) entendem que o poder regulador é proveniente da delegação de competências do Poder Legislativo e Executivo às agências reguladoras para que possam, de fato, cumprir o seu papel de agente regulador, atendendo

\footnotetext{
10 termo captura refere-se à condição em que o órgão regulador toma decisões técnicas baseadas no atendimento aos interesses específicos dos agentes econômicos regulados, numa afronta flagrante à própria razão de existir de um órgão regulador.

2 Entende-se como seleção adversa, nesse contexto, a situação em que uma operadora de planos de saúde seleciona, sem ter o conhecimento prévio, um indivíduo com problemas de saúde e que será um utilizador em potencial de seu plano de saúde.

3 Risco moral aqui tratado é a situação em que o beneficiário de plano de saúde aumenta a utilização dos serviços do plano sem uma necessidade de saúde que justifique a sobreutilização do plano.

4 Assimetria de informação é quando, por exemplo, a operadora de planos de saúde detém mais informação a respeito das garantias contratuais do plano de saúde que está vendendo do que o beneficiário que está comprando esse plano.

5 Externalidades referem-se ao impacto de uma decisão sobre aqueles que não participaram dessa decisão. Por exemplo: a ANS estabelece, através de normativo, o percentual de reajuste dos planos individuais em razão da variação de custo dos planos de saúde coletivos (que são decorrentes da incorporação de tecnologia, aumento dos custos dos serviços médico-hospitalares, entre outros). Para o beneficiário, o impacto é negativo, pois terá de pagar um valor maior de mensalidade de seu plano de saúde (Teixeira, 2oo1).
} 
às necessidades do setor específico, de acordo com os princípios jurídicos vigentes.

Ao propor e executar políticas públicas referentes aos seus respectivos setores, as Agências reguladoras ultrapassam os limites da regulação. Seu poder normativo é questionado, fundamentalmente, porque as normas expedidas pelas Agências não são elaboradas por representantes democraticamente eleitos pelo povo e, dessa forma, não possuem a representatividade necessária para serem válidas. Entretanto, Ventura (2004) expõe que esse poder legislativo das Agências é uma forma de aprofundamento da função normativa do Estado, visto que apenas leis gerais são insuficientes para defender e regular o interesse público. Nesta perspectiva e exatamente por estes motivos, ambiente em constante mudança e ineficácia de leis gerais para a garantia do interesse público no mercado regulado pelas agências reguladoras, é que se justifica uma atuação normativa delegada pelo legislador que cria e estipula os limites da atuação das agências reguladoras. Logo, pode-se dizer que a agência reguladora é um braço do poder legislativo, atuando nos limites da Lei que a criou, com a finalidade de criar políticas e instrumentos normativos para o setor de sua competência, pautando-se nos princípios de eficiência, celeridade e robustez técnica de suas decisões. Com um corpo funcional técnico e especializado, atuando somente em algumas áreas específicas, é possível a consecução de diretrizes mais adequadas para o setor regulado.

Cabe elucidar que, justamente, pela composição da direção das agências reguladoras não serem fruto de um processo democrático de eleição de seus representantes, todo ato normativo emanado por uma agência reguladora deve passar por um processo de consulta pública para ser válido. 0 processo de consulta pública, segundo Ventura (2004), nada mais é do que a democracia participativa no âmbito da Administração Pública, em complementação à tradicional democracia representativa, configurada através da manifestação pública de todos os agentes regulados na discussão, a apresentação de críticas e sugestões quanto aos atos normativos a serem publicados pela agência.

Contudo, é necessária a formulação de políticas e diretrizes para os setores regulados. No setor da saúde suplementar, por exemplo, hoje é inaceitável admitir-se que indivíduos com moléstias incuráveis sejam impedidos de participar de planos de saúde, ou que determinadas doenças, como o câncer ou a depressão, não tenham cobertura contratual, o que era perfeitamente previsível em contratos anteriores à edição da Lei 9.656 de 1998 (Costa, 2008).

As agências reguladoras também se configuram como espaços de mediação de conflitos entre os atores componentes do mercado regulado, buscando solucionar situações em que haja interesses regulados divergentes. Assim, ao mediarem ativamente esses conflitos, por meio de seus instrumentos regulamentadores, que permitem um atuar legal e transparente durante todo o processo, surgiu a ideia de que esta ação se configura uma atuação quase judicial.

Com seu poder mediador, as agências reguladoras buscam a resolução do conflito pelo consenso entre as partes, monitorando o processo de negociação, sem que uma das partes (o administrado) tenha que cumprir uma determinada decisão. Entretanto, quando essa mediação fracassa, diante de uma situação em que haja lesão a algum direito ou a alguma norma setorial, a agência reguladora, obrigatoriamente, deve posicionar-se no sentido de aplicar a sanção correspondente, de acordo com os regramentos setoriais vigentes.

Portanto, observa-se que, não obstante ter a agência reguladora um papel importante na composição dos conflitos dos entes que compõem o setor regulado, também atua fiscalizando e punindo os administrados quando estes infringem as regras do setor regulado. A Agência Nacional de Saúde Suplementar é uma agência reguladora criada com a finalidade de regular o mercado de planos de saúde e que será foco de análise no tópico seguinte.

\section{A Agência Nacional de Saúde Suplementar - ANS}

No Brasil, uma característica do sistema de saúde, anteriormente ao marco constitucional de 1988, era a livre atuação entre iniciativas públicas e privadas no que tange ao oferecimento, financiamento e operação dos serviços de saúde.

Devido ao aumento crescente do setor privado no financiamento e oferta dos serviços de saúde, por meio de empresas que intermediavam o pagamento dos serviços dispensados às pessoas que os contra- 
tavam, o Estado, que acabou por se afastar, em parte, da prestação da assistência à saúde, passa a assumir novo papel, agora na regulação desse tipo de assistência prestada por meio de empresas privadas.

Com o objetivo de regulamentar as relações existentes nesse setor da economia ${ }^{6}$, Bahia (2001) relata que o Decreto-Lei n$^{\circ}$ 73/66 foi o primeiro instrumento que dispunha sobre a comercialização de planos e seguros de saúde. Todavia, deixou de fora empresas de medicina de grupo "não lucrativas" (e também cooperativas médicas), que operaram até o ano de 1998 sem nenhuma regulamentação Estatal.

Sato (2007) descreve que a expansão do setor suplementar de assistência à saúde (setor caracterizado pela operação de planos de saúde) foi acompanhada pelo aumento de distúrbios nas relações entre usuários e operadoras de planos de saúde, estando relacionados, principalmente, a negativas de coberturas assistenciais, aumento nos preços das mensalidades dos planos de saúde e interrupção de atendimento. Nesse período, o poder judiciário, embasado no Código de Defesa do Consumidor, atuou no sentido de conceder liminares favoráveis ao atendimento dos usuários. Neste contexto, entidades médicas e órgãos de defesa do consumidor aliaramse e passaram a exercer uma pressão social para a existência de uma regulamentação para o setor.

Sobre os marcos pontuais da regulamentação do setor suplementar de saúde, o mesmo autor acrescenta que, em 1993, começaram a tramitar no Senado Federal projetos acerca da regulamentação do setor suplementar que tinham dois objetivos principais: o ressarcimento ao Sistema Único de Saúde e a ampliação de cobertura assistencial. Em 1997, foi formada uma comissão para tratar da regulamentação e, em 1998, foi promulgada a Lei n⿳ำ 9.656/98, como resposta ao clamor de alguns segmentos sociais pela regulamentação de um setor em crescente e desorientado crescimento. Assim, isso trouxe de imediato alguns significativos avanços que se traduziam em obrigações para as empresas que atuavam como operadoras de planos de saúde (Brasil, 1998a). Dentre os mais notórios, podem-se citar:

- a obrigatoriedade de atendimento para todas as doenças relacionadas na Classificação Internacional de Doenças (CID);

- proibição da negativa de cobertura a procedimentos relacionados com doenças ou lesões preexistentes;

- limites para os reajustes nas mensalidades dos planos de saúde;

- limitação dos tempos máximos de carências;

- proibição da rescisão unilateral de contratos de planos de saúde;

- proibição da seleção de risco7;

- garantia de internação sem limite de dias;

- ressarcimento, pelas operadoras, dos atendimentos prestados a seus beneficiários no Sistema Único de Saúde.

Adverte-se, ainda, que as inovações produzidas pela Lei nº 9.656/98 não se encerram nessas matérias, podendo ainda serem mencionados outros avanços alcançados, como a ênfase nas ações de promoção à saúde e prevenção de doenças, o ato de priorizar o uso de sistemas de informação para melhor monitoramento do setor regulado e a exigência de contratos mais transparentes.

De fato, o arcabouço engendrado pela Lei $\mathrm{n}^{\mathrm{o}}$ 9.656/98 acarretou mudanças nas relações entre os agentes do setor regulado - operadoras, prestadores de serviços e beneficiários de planos de saúde ${ }^{8}$,

6 Assim entendido porque gerava renda para o Estado, através não só da prestação de serviços de saúde, mas também pelos investimentos em tecnologias nessa área.

7 Seleção de risco é uma falha de mercado entendida como uma situação na qual a operadora de planos de saúde rejeita a entrada de um indivíduo em um plano de saúde ao ter o conhecimento, através do preenchimento da declaração de saúde ou de realização de perícia médica neste beneficiário, que ele é portador de alguma doença ou transtorno e, por esse motivo, terá uma probabilidade maior de utilizar o plano de saúde e, dessa forma, onerar a operadora. Logicamente, a operadora procurava selecionar indivíduos sadios, com baixo risco para a utilização do plano, pois dessa maneira incorreria em menos gastos. Ao se tornar proibida a seleção de risco, os indivíduos que queriam adquirir um plano de saúde, mas não eram aceitos pelas operadoras em função de doenças ou condições prévias, passaram a ter um direito, definido em Lei, de serem aceitos por qualquer operadora de planos de saúde, independentemente de suas condições de saúde (Teixeira, 2001).

8 É conveniente esclarecer que, no setor suplementar de assistência à saúde, o beneficiário de plano de saúde é o indivíduo que assina um contrato com uma operadora de planos de saúde, que lhe dá o direito de utilizar os serviços de saúde descritos nesse contrato, a uma contraprestação pecuniária (mensalidade) paga à operadora de planos de saúde. Esta, por sua vez, recebe a contraprestação e paga aos prestadores credenciados os serviços de saúde utilizados por seus beneficiários. 
isso porque a relação entre esses agentes passou a estar baseada em instrumentos normativos que restringem a atuação das operadoras, estimulando a competição entre essas empresas, fundamentada, basicamente, nos preços e nos mecanismos de regulação do acesso dos beneficiários aos serviços de saúde, uma vez que a cobertura mínima e essencial passou a ser determinada por Lei.

Em 2001, através da Lei federal no 9.961, foi criada a ANS como uma autarquia sob regime especial, vinculada ao Ministério da Saúde, com atuação em todo o território nacional, como órgão de regulação, normatização, controle e fiscalização das atividades que garantem a assistência suplementar à saúde. Essa mesma lei conferiu à ANS a finalidade institucional de promover a defesa do interesse público na assistência suplementar à saúde, regulando as operadoras setoriais, inclusive quanto às suas relações com prestadores e consumidores, contribuindo para o desenvolvimento das ações de saúde no País (Brasil, 200o).

A ANS surgiu, portanto, para regular um mercado de planos privados de assistência à saúde que, até aquele momento (quase 40 anos após o surgimento das primeiras operadoras de planos de saúde), atuava sem qualquer intervenção do poder Estatal, operando por mecanismos bastante frágeis, sobretudo quanto ao nível de informação ao consumidor (Costa, 2008). Além disso, o beneficiário, ou seja, a pessoa que contratava um plano de saúde ficava totalmente entregue a cláusulas contratuais abusivas, visto que, ao assinar o contrato, estava, tacitamente, de acordo com cláusulas que excluíam doenças e lesões preexistentes, enfermidades incuráveis, procedimentos de alta complexidade e que, inclusive, limitavam os dias de internação hospitalar.

0 marco regulatório introduzido pela Lei $\mathrm{n}^{\circ}$ 9.656/98 - que dispõe sobre os planos e seguros privados de assistência à saúde e pela Lei no 9.961/oo - que cria a ANS, transformou substancialmente o cenário da falta de regulamentação, com a edição de um arsenal de normativos que tratavam desde regras para a entrada e saída de operadoras de planos de saúde no mercado até a proteção de direitos dos beneficiários de planos de saúde.

A atuação da ANS veio combater algumas práticas abusivas, procurando garantir, através de um arcabouço normativo, o desenvolvimento de contratos que ofertassem um rol mínimo assistencial, sem limites de consultas médicas e de internação, reajustes financeiros controlados e seguindo critérios predeterminados, acesso igualitário a portadores de doenças preexistentes, uma qualidade mínima nos serviços de saúde prestados, dentre outros avanços. Assim, nos novos contratos, as operadoras de planos de saúde são obrigadas a cobrir doenças como o câncer, a AIDS e transtornos psiquiátricos e estão proibidas de negar assistência a beneficiários que já ingressam no plano com uma doença prévia.

O exercício do dever legal da ANS é baseado em resoluções normativas e instruções de serviços, editados por essa agência reguladora para estabelecer os regramentos desse subsetor. Todo normativo é submetido à diretoria colegiada da ANS, composta por cinco diretores, que decide sobre a aprovação de tais regras. Uma vez aprovado, o normativo está pronto para entrar em vigor e produzir seus efeitos. Dessa forma, as operadoras têm o dever de seguir e de se adequar a tais diretrizes e, quando deixam de observá-las, podem estar sujeitas às penalidades previstas na legislação setorial.

Assim, de acordo com a Lei no 9.961/oo, entre outras ações, compete à ANS estabelecer parâmetros de cobertura assistencial para os serviços próprios e de terceiros oferecidos pelas operadoras, bem como zelar pelo cumprimento desses parâmetros, os quais são oriundos de políticas de atenção à saúde específicas para o setor regulado. Dentre outros assuntos relativos à cobertura assistencial, está a política de atenção à saúde mental no setor.

\section{As Políticas de Atenção à Saúde Mental no Setor Suplementar de Saúde}

Anteriormente à Lei nํㅗ 9.656/98, não existia nenhum regramento para a atenção à saúde mental no sistema operado pelos planos de saúde, havendo apenas as portarias emanadas pelo Ministério da Saúde que abrangiam somente os prestadores de assistência à saúde mental (hospitais e clínicas) em suas relações com o SUS. Com exceção da Portaria SAS/ n 145 (Brasil, 1994), que teve como objetivo 
criar um subsistema de supervisão, controle e avaliação da assistência em saúde mental, pelos diversos níveis do SUS, as demais faziam referência, quase que exclusivamente, a procedimentos para cadastros de hospitais para internação psiquiátrica no âmbito do SUS, serviços, cobranças e normas para alimentação dos Sistemas de Informação Ambulatorial e Hospitalar (SIA e SIH).

As políticas de atenção à saúde mental do setor suplementar de assistência à saúde estão dispostas em duas resoluções normativas - Resolução CONSU nํㅜㄹ, publicada em 4 de novembro de 1998 , que dispõe sobre a cobertura aos tratamentos de todos os transtornos psiquiátricos codificados na Classificação Estatística Internacional de Doenças e Problemas Relacionados à saúde - CID-1o (Brasil,

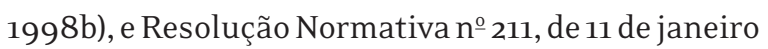
de 2010, que atualiza o rol de procedimentos e eventos em saúde, constituindo a referência básica para cobertura assistencial mínima nos planos privados de saúde, contratados a partir de $1^{\circ}$ de janeiro de 1999 (Brasil, 2010) e que revoga a Resolução CONSU nํำ1. A seguir, será realizada a análise dos dois normativos, começando-se com a resolução mais antiga.

Verifica-se que o preâmbulo da Resolução CONSU nํำ enfatizou a importância da adoção de medidas que buscassem a diminuição da estigmatização e da hospitalização dos portadores de transtornos mentais, em claro alinhamento às políticas instituídas pela reforma psiquiátrica no âmbito do SUS, que visavam "ao resgate da cidadania e da singularidade dos sujeitos" (Suiyama e col., 2007, p.103), por meio da desospitalização e da criação de uma rede assistencial substitutiva composta por serviços comunitários abertos.

Nota-se também que, logo no artigo $1^{\circ}$, a resolução obrigou as operadoras de planos de saúde a oferecerem cobertura a todos os transtornos psiquiátricos codificados na CID-1o. É importante salientar que, exatamente na mesma data de publicação desse normativo, foi detalhada uma série de procedimentos na Resolução CONSU nํㅜ일, que, à época, era a referência de cobertura assistencial mínima pelas operadoras de planos de saúde. Entretanto, a assistência à saúde mental ficou fora do referido corpo do normativo, sendo tratada à parte por outra resolução. Tal fato pode demonstrar um tratamento desigual dado aos transtornos mentais, visto que o normativo específico que diz respeito à temática trouxe uma série de restrições que não foram colocadas para outros tipos de doenças e agravos à saúde.

0 artigo $1^{\circ}$ fez ainda referência ao obedecimento de normas complementares que viessem a ser expedidas pelo Ministério da Saúde, mas não houve a publicação de nenhum outro normativo, seja pelo próprio Ministério, seja pela ANS, que reestruturasse a atenção à saúde mental no setor suplementar, mesmo após a publicação da Lei nํㅜㅅ‥216, de 6 de abril de 2001, que redireciona o modelo de atenção em saúde mental (Brasil, 2001). Isso só viria a ocorrer quase dez anos após a publicação da citada Lei, por meio da RN nํㅜ 211, de 2010.

A Resolução CONSU no 11 trouxe também a divisão da cobertura assistencial em planos de segmento ambulatorial e de segmento hospitalar, devido ao fato de que a cobertura a ser obrigatória iria depender fundamentalmente da segmentação do plano contratado. Neste contexto, no atendimento ambulatorial, ficaram assegurados a atenção em caso de emergências (situações nas quais haja risco de morte para o paciente ou danos físicos para o próprio ou para terceiros), a psicoterapia de crise e o tratamento básico, em regime de consulta, realizado por médico assistente. $\mathrm{O}$ artigo $2^{\circ}$, item I, alínea “a” considerou as ameaças e tentativas de suicídio como situação de risco de vida e, por este motivo, seu atendimento caracterizou-se como cobertura obrigatória pelas operadoras de planos de saúde, o que foi um grande avanço para os usuários desse subsetor. Nos contratos anteriores à Lei n⿳o 9.656/98, as tentativas de suicídio eram excluídas por serem situações autoprovocadas. Esse normativo entendeu a tentativa de suicídio como consequência de um transtorno psiquiátrico e que, por esse motivo, deveria ter assegurado o seu tratamento.

O mesmo artigo foi objetivo ao garantir a cobertura apenas para a psicoterapia de crise. Diante do contexto exposto pela alínea “a”, pode-se entender crise, de acordo com a definição de Carvalho e Costa (2008), como um atendimento de emergência quando o indivíduo está em uma situação de desequilíbrio psíquico, estando desprovido das competências que o levam a uma reacomodação às situações de 
conflito. Outrossim, o próprio normativo não trouxe uma definição clara do que seja crise. Não se pode deixar de reconhecer que um avanço trazido por este item é o fato de a psicoterapia de crise poder ser prestada por um ou mais profissionais da área de saúde mental, não sendo restringida ao atendimento médico. Entretanto, a psicoterapia, com equipe multiprofissional, ou com psicólogos, para o tratamento de transtornos psiquiátricos de longa duração, ficou excluída da resolução. O número de sessões de atendimento também foi limitado a 12, o que poderia não ser uma quantidade suficiente para tratar transtornos psiquiátricos de longa duração.

A Resolução CONSU nº 15/99 alterou a Resolução CONSU nํㅜㄴ $11 / 98$, acrescentando ao artigo $2^{\circ}$, item I, alínea "b” e item II, alíneas “a” e "b”, que as 12 sessões de psicoterapia não eram cumulativas, ou seja, não poderiam ser acumuladas de um ano de contrato para o outro. Sendo assim, mesmo que o beneficiário não utilizasse as sessões de psicoterapia dentro de um ano de contrato, não poderia somar essas sessões às do ano de contrato seguinte, tendo direito, somente, a 12 sessões por ano.

Por outro lado, a alínea "c" do item I do artigo $2^{\circ}$ estabeleceu um tratamento básico, definido como a prestação do serviço pelo médico assistente, com número ilimitado de consultas e demais procedimentos. Pode-se concluir, então, que, se o tratamento psiquiátrico fosse realizado pelo médico assistente, não haveria restrições quanto ao número de consultas e demais procedimentos necessários ao diagnóstico e ao tratamento do beneficiário. Contudo, se o beneficiário necessitasse realizar psicoterapia de longa duração, não teria esse direito garantido, mesmo que fosse realizado por médico assistente.

Para o plano hospitalar, essa mesma resolução, no artigo $2^{-}$, item II, estabeleceu o "custeio integral de, pelo menos, 30 dias de internação, por ano” (Brasil, 1998b), em decorrência de transtornos psiquiátricos, somente em situação de crise. A cobertura para casos de dependência química, intoxicação e alcoolismo foi limitada de igual forma, porém em um período de até 15 dias de internação, por ano, o que configurava uma hospitalização com objetivo de tratamento de casos agudos. Caso houvesse coparticipação para internação psiquiátrica, a mesma regra deveria valer, também, para as internações das outras especialidades médicas.

Essa constatação não objetiva incentivar a modalidade de tratamento hospitalizada, o que seria um retrocesso, mas, sim, refletir que, nesses casos, o beneficiário não teve direito ao custeio integral de sua internação, da forma como ocorria com as internações de outra natureza, o que demonstra, mais uma vez, um tratamento diferenciado dado pela ANS às internações psiquiátricas.

Outrossim, nos artigos $1^{\circ}, 2^{\circ}$ e $3^{\circ}$, a resolução permitiu a utilização da coparticipação e franquia do beneficiário no custeio de sua internação. A franquia e a coparticipação são fatores moderadores da utilização do plano de saúde pelo beneficiário. Nesse caso, para um plano de saúde que tivesse coparticipação para internação, se o beneficiário necessitasse ser internado e já tivesse utilizado os 30 dias de internação a que tinha direito com custeio integral pela operadora, pagaria um valor fixo por dia de internação. 0 mesmo artigo permitiu, também, que essa participação fosse crescente, conforme o tempo de internação.

A ênfase dedicada à coparticipação nas internações psiquiátricas não se sucedeu com as internações de outra natureza nos normativos da ANS, o que pode ser justificado pelo longo curso de duração das internações psiquiátricas que, por conseguinte, geram custos altos para as operadoras de planos de saúde. Ressalta-se, entretanto, que a função de um fator moderador não deve ser a de dividir os custos da assistência com o beneficiário, mas, sim, impedir a utilização indevida ou desnecessária do plano de saúde. Embora o interesse aqui fosse a diminuição de custos pela operadora, pode ter ocorrido um efeito adverso, benéfico para a política de saúde mental e para o paciente: no caso de uma internação, a pressão para a desospitalização, exercida pela operadora e também pela família (que teria de pagar a coparticipação crescente), poderia ser maior e, com isso, ser menor o tempo de internação do beneficiário.

Em contrapartida, o artigo $4^{\circ}$ trouxe um ganho importante para o tratamento dos transtornos mentais, colocando-os em patamar privilegiado às demais doenças listadas na CID-10, ao garantir um prazo máximo de cobertura parcial temporária $^{9}$ de 180 dias, excluindo apenas as internações decorrentes de transtornos psiquiátricos por uso 
de substâncias químicas. Os demais instrumentos normativos da ANS estabelecem um prazo máximo de 24 meses de cobertura parcial temporária para as doenças preexistentes (Brasil, 2007). Logo, um beneficiário que ingressasse em um plano de saúde com um diagnóstico de esquizofrenia, relatado em sua declaração de saúde, só não poderia utilizar o plano para internação, em virtude dessa doença, durante os primeiros 180 dias de contrato.

Outra novidade foi a introdução da modalidade de assistência à saúde mental dispensada pelo hospital-dia, entidade vinculada ao modelo psiquiátrico reformado do SUS. Todavia, aqui também houve limitação de oito semanas de tratamento por ano em regime de hospital-dia, estendendo-se essa assistência para 180 dias por ano para alguns transtornos específicos, como, por exemplo, demências, esquizofrenias, psicoses, retardos mentais e alguns transtornos de comportamento e transtornos emocionais.

Em 11 de janeiro de 2010, foi publicada a Resolução Normativa no 211, que atualizou o rol de procedimentos e eventos de saúde. Na realidade, o novo normativo incorpora alguns artigos da Resolução CONSU no 11/98, revogada em decorrência de sua publicação, e amplia alguns benefícios ao portador de transtorno mental, sendo possível verificar uma tentativa de alinhamento da ANS às políticas públicas de saúde mental.

$\mathrm{O}$ inciso $\mathrm{V}$ do artigo $3^{\circ}$, que estatui os princípios de atenção à saúde, na saúde suplementar, reitera o preâmbulo da CONSU no ${ }^{11 / 98}$, enfatizando a "adoção de medidas que evitem a estigmatização e a institucionalização dos portadores de transtornos mentais" (Brasil, 2010, p. 2). 0 artigo 9ํé ainda mais expressivo ao estabelecer que a atenção ao portador de transtorno mental deve priorizar o atendimento ambulatorial e que a internação psiquiátrica deverá ser o último recurso, e nas ocasiões em que for indicada pelo médico assistente. Aqui, parte-se do pressuposto de que o médico assistente só indicará a internação se ela realmente for inevitável. Entretanto, não é possível ter-se essa garantia, já que coexistem outros paradigmas assistenciais em saúde mental que não apenas o que defende a desospitalização. 0 mesmo artigo ratifica que estão cobertos todos os procedimentos médicos decorrentes de transtornos mentais, inclusive aqueles para tratamento de lesões autoinfligidas.

No plano de segmentação ambulatorial, os incisos IV e V, do artigo 17, definem o acesso a sessões com psicólogo, com terapeuta ocupacional e de psicoterapia (realizada por psicólogo ou médico habilitado), por meio de diretrizes de utilização. Essas diretrizes, constantes da Instrução Normativa DIPRO nํ․ 25, de 14 de janeiro de 2010, determinam o número máximo de 40 sessões com psicólogo e/ou terapeuta ocupacional, e de 12 sessões para psicoterapia, por ano de contrato, de acordo com o diagnóstico, baseado no código da CID, que o beneficiário de plano de saúde tenha recebido. As indicações para esses tratamentos são basicamente os mesmos citados na revogada Resolução CONSU nํㅜ11/98, com o acréscimo de alguns transtornos relacionados ao desenvolvimento psicológico e de humor.

Apesar de ser um reconhecido avanço o aumento do número de atendimento com psicólogo ou terapeuta ocupacional, a limitação pelo preenchimento dos critérios das diretrizes de utilização pode constituir uma barreira para o tratamento de beneficiários que sofram de transtornos mentais não contemplados nas diretrizes estabelecidas. Ou pior: essa limitação pode significar a codificação de um diagnóstico não verdadeiro, mas que dê acesso ao seu tratamento.

No plano de segmentação hospitalar, artigo 18, apesar de o texto normativo ser apresentado de forma diferente, não houve qualquer mudança significativa na política de atenção à saúde mental. A cobertura das internações psiquiátricas manteve-se da mesma forma que na Resolução CONSU nํ11/98: deve ser custeada de acordo com o contrato; a coparticipação, se estabelecida, não pode ser diferente nas internações de outras especialidades, sendo permi-

\footnotetext{
9 Cobertura parcial temporária é aquela que admite, por um período ininterrupto de até 24 meses, a partir da data da contratação ou adesão ao plano privado de assistência à saúde, a suspensão da cobertura de Procedimentos de Alta Complexidade (PAC), leitos de alta tecnologia e procedimentos cirúrgicos, desde que relacionados, exclusivamente, às doenças ou lesões preexistentes declaradas pelo beneficiário ou seu representante legal (Brasil, 2007).
} 
tida a coparticipação crescente para as internações psiquiátricas que ultrapassarem 30 dias no decorrer de um ano de contrato.

A cobertura de hospital-dia para transtornos mentais sofreu alterações quantitativas e qualitativas. O normativo em vigor reduziu o número de transtornos mentais cobertos pelo hospital-dia, de 39 para 15 tipos de transtornos, e alterou os diagnósticos psiquiátricos que possuem indicação para esse tipo de tratamento. Examinando-se todas as diretrizes de utilização para tratamentos de transtornos mentais, é possível observar que os diagnósticos com tratamento recomendado em hospital-dia pela Resolução CONSU no $11 / 98$ foram distribuídos nessas diretrizes (sessões com psicólogo, terapeuta ocupacional, psicoterapia e acompanhamento em hospital-dia). Assim, ao que parece, o beneficiário terá direito a um tipo de tratamento em forma de sessão e, em alguns casos, poderá usufruir do hospital-dia também. Uma novidade promissora é que não há mais limite temporal para o atendimento em hospital-dia. 0 tempo fica a critério médico.

Mais de 10 anos se passaram entre a publicação da primeira e da segunda resolução normativa sobre a política de saúde mental no sistema suplementar de saúde e, como se pode constatar, quase não houve alterações significativas entre uma e outra. Por outro lado, questões elementares nessa seara permaneceram sem a devida regulação da ANS.

A ANS possui, dentre suas competências legais relativas à assistência à saúde, a elaboração do rol de procedimentos, a fixação de critérios para procedimentos de credenciamento e descredenciamento de prestadores de serviços às operadoras, o estabelecimento de parâmetros e indicadores de qualidade e de cobertura assistenciais, a fiscalização das atividades das operadoras, o controle e a avaliação dos aspectos relacionados à garantia de acesso, à manutenção e à qualidade dos serviços prestados, direta ou indiretamente, pelas operadoras, a avaliação da capacidade técnico-operacional das operadoras para garantir a compatibilidade da cobertura oferecida com os recursos disponíveis na área de abrangência geográfica e o zelo pela qualidade dos serviços de assistência à saúde suplementar.

Observa-se que todas essas atribuições deixam muito claro a obrigação da ANS em definir, controlar e avaliar a qualidade dos serviços assistenciais oferecidos pelas operadoras de planos de saúde através, principalmente, de sua rede prestadora. Todavia, apesar de já existir há mais de dez anos, a agência pouco avançou no que diz respeito à definição de critérios de qualidade de serviços de saúde e seu monitoramento, sobretudo no que diz respeito aos serviços de saúde mental.

A definição de critérios para credenciamento e descredenciamento de prestadores de serviços de saúde mental também não foi estabelecida ainda, bem como parâmetros de qualidade para os serviços de cobertura obrigatória e, em consequência, também não existem critérios para a aferição e o controle da qualidade dos serviços de saúde mental ofertados. Logo, a avaliação da garantia do acesso, da qualidade dos serviços prestados e o zelo pela qualidade desses serviços resta prejudicada, pela ausência de regulamentos objetivos e da própria atividade da ANS. Por conseguinte, hoje, não se conhecem as características da rede assistencial de saúde mental dos planos de saúde, dos serviços ofertados nem como se está realizando o acesso dos seus usuários ao sistema, não sendo possível concluir sobre a qualidade desses serviços.

É possível perceber, por meio dos instrumentos normativos da ANS e da efetivação de suas ações, que a maior preocupação regulatória ao longo desses anos tem sido com os aspectos econômicofinanceiros das operadoras. Sem dúvida, o equilíbrio desses elementos é parte primária e fundamental para a existência saudável de uma empresa que objetiva operar no mercado de planos de saúde e, por esse motivo, eles devem ser monitorados com certa prioridade. Porém, a agência não pode renunciar ao seu papel de regulador da assistência, visto que essa é uma característica definida em Lei e de essencial execução para a garantia do interesse público.

\section{Considerações Finais}

Após a criação da ANS, pela Lei no 9.961, de 2000, portanto, em momento posterior à Resolução CONSU n-11/98, foi publicada a RN nํ․ 211, de 2010, que, em síntese, não traz alterações significativas à política de saúde mental no sistema suplementar de saúde. Entretanto, mais de 10 anos se passaram entre uma 
e outra resolução, e questões importantes da saúde mental nesta seara permanecem sem a devida regulamentação e monitoramento. Diga-se, ainda, que também não houve qualquer intenção, na Resolução

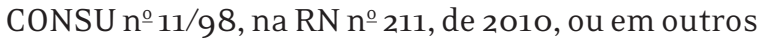
normativos publicados pela ANS, de fiscalizar a qualidade da assistência prestada pelas instituições de saúde mental credenciadas aos planos de saúde, considerando que a monitorização da qualidade da rede credenciada da operadora, bem como da assistência ofertada por ela fazem parte das atribuições legais da ANS.

Apesar da existência dessas lacunas, não se pode desconsiderar a relevância de tais normas para os beneficiários de planos de saúde, uma vez que abarcaram mudanças positivas em um cenário marcado por contratos injustos e excludentes, que colocavam o beneficiário em uma situação prejudicial (Costa, 2008). Então, a obrigatoriedade de cobertura para todas as doenças listadas na CID-10, a inclusão do tratamento das tentativas de suicídio e das lesões autoinfligidas, o atendimento por uma equipe multiprofissional, a ampliação do número de sessões com psicólogo, com terapeuta ocupacional e de psicoterapia, e o estabelecimento ilimitado de cobertura para hospital-dia foram introduções normativas benéficas para os usuários do sistema suplementar de saúde.

Nessa perspectiva, ainda são necessárias adequações da norma vigente às políticas públicas de saúde mental, considerando as particularidades desse subsetor. Os mecanismos de regulação do plano de saúde, como coparticipação e franquias, precisam ser mais bem disciplinados, de forma a não restringir o acesso do beneficiário ao plano quando ele necessite utilizá-lo. Atualmente, não há nenhum normativo que estabeleça o valor máximo a ser pago a título de franquia e coparticipação por consulta, hospital-dia ou dia de internação.

A coparticipação crescente para as internações psiquiátricas também necessita ser repensada sob a óptica da cobertura integral de serviços de saúde mental que componham uma rede substitutiva ao hospital psiquiátrico, que garanta o atendimento integral e contínuo do beneficiário por meio de ambulatórios, de hospitais-dia e de atendimento multiprofissional. A psicoterapia restringida a 12 sessões é outro fator preocupante. Pode-se inferir que esse número está muito aquém do ideal para tratar transtornos mentais, sendo insuficiente para garantir um tratamento eficaz a indivíduos com essas demandas, fundamentalmente porque uma de suas características é a longa duração, podendo haver a necessidade de um tratamento contínuo e prolongado (Lowenkron, 2006).

O hospital-dia, apesar de ser um elemento incorporado da política pública de saúde mental, foi fixado somente para a segmentação dos planos hospitalares. Logo, os beneficiários de planos da segmentação ambulatorial não têm cobertura para tratamento naquele tipo de entidade. Tal fato demonstra um descompasso entre as diretrizes do Ministério da Saúde e as da ANS, visto que o beneficiário de um plano da segmentação ambulatorial, se necessitar, pode vir a buscar no SUS este tipo de atendimento. É preciso avançar na constituição da rede extra-hospitalar, substitutiva ao hospital psiquiátrico. $\mathrm{O}$ hospital-dia pode ser uma boa estratégia para o alcance desse objetivo.

De todo modo, alguns passos já foram dados no sentido de garantir assistência aos portadores de transtornos mentais, usuários de planos de saúde. Porém, muito se precisa avançar para garantir o alinhamento e a qualidade assistenciais da saúde mental praticada no modelo suplementar de saúde às políticas de saúde mental ministeriais. Para que isso aconteça, é fundamental que a ANS, em primeiro lugar, aproprie-se de suas competências legais relativas à assistência, que atue sob um consistente marco regulatório, que defina claramente suas atribuições enquanto órgão normatizador, regulador e fiscalizador, que estude e analise a situação da atenção à saúde mental no sistema suplementar (quantitativo de prestadores de saúde mental na rede da operadora, caracterização dos serviços ofertados por esses prestadores, qualidade da assistência dispensada aos beneficiários) para propor estratégias que visem à melhoria dessa assistência, que fiscalize as operadoras e prestadores quanto à prestação da assistência e que dê uma resposta célere e eficiente à sociedade na mediação ativa dos conflitos que envolvam essas questões, para que, realmente, possa cumprir sua finalidade institucional de promover a defesa do interesse público na assistência suple- 
mentar à saúde e contribua, de forma efetiva, para o desenvolvimento das ações de saúde, neste caso, das ações de saúde mental no País.

\section{Referências}

BAHIA, L. O mercado de planos e seguros de saúde no Brasil: tendências pós-regulamentação. In: NEGRI, B.; GIOVANNI, G. di (Org.). Brasil: radiografia da saúde. Campinas: Unicamp, 2001. p. 325-361.

BRASIL. Ministério da Saúde. Portaria SAS n. ${ }^{\circ}$ 145, de 25 de agosto de 1994. Cria um subsistema de supervisão, controle e avaliação da assistência em saúde mental, com o objetivo de acompanhar e avaliar, junto aos estabelecimentos prestadores de serviços do SUS, a correta aplicação das normas em vigor. Diário Oficial da União, Brasília, DF, 29 ago. 1994. Seção 1, p. 9.

BRASIL. Lei n. ${ }^{\circ}$ 9.656, de 3 de junho de 1998. Dispões sobre os planos privados de assistência à saúde. Diário Oficial da União, Brasília, DF, 4 jun. 1998a. Seção 1, p. 1.

BRASIL. Agência Nacional de Saúde Suplementar ANS. Resolução CONSU n. ${ }^{\circ} 11$, de 4 de novembro de 1998. Dispõe sobre a cobertura aos tratamentos de todos os transtornos psiquiátricos codificados na Classificação Estatística Internacional de Doenças e problemas relacionados à saúde. Diário Oficial da União, Brasília, DF, 4 nov. 1998b. Secção 1, p. 3 .

BRASIL. Lei n. ${ }^{\circ}$ 9.961, de 28 de janeiro de 2000. Cria a Agência Nacional de Saúde Suplementar - ANS e dá outras providências. Diário Oficial da União, Brasília, DF, 29 jan. 2000 . Seção 1, p. 5.

BRASIL. Lei n. ${ }^{\circ}$ 10.216, de 6 de abril de 2001. Dispõe sobre a proteção e os direitos das pessoas portadoras de transtornos mentais e redireciona o modelo assistencial em saúde mental. Diário Oficial da União, Brasília, DF, 9 abr. 2001. Seção 1, p. 2.

BRASIL. Conselho Nacional de Secretários de Saúde. SUS: avanços e desafios. Brasília, DF, 2006.
BRASIL. Agência Nacional de Saúde Suplementar. Resolução normativa n. ${ }^{\circ} 162$, de 17 de outubro de 2007. Estabelece a obrigatoriedade da Carta de Orientação ao Beneficiário e dá outras providências. Diário Oficial da União, Brasília, DF, 18 out. 2007 . Seção 1, p. 40.

BRASIL. Agência Nacional de Saúde Suplementar. Resolução normativa n. ${ }^{\circ}$ 211, de 11 de janeiro de 2010. Atualiza o rol de procedimentos e eventos em saúde, que constitui a referência básica para cobertura assistencial mínima nos planos privados de assistência à saúde e dá outras providências. Disponível em: http://www.ans. gov.br/modules/mod_legislacao/exibir/texto_lei. php?id=1575. Acesso em: 16 fev. 2012.

CARVALHO, N. R. de; COSTA, I. I. da. Primeiras crises psicóticas: identificação de pródromos por pacientes e familiares. Psicologia Clínica, Rio de Janeiro, v. 20, n. 1, p. 153-164, 2008.

COSTA, N. do R. O regime regulatório e o mercado de planos de saúde no Brasil. Ciência \& Saúde Coletiva, Rio de Janeiro, v. 13, n. 5, p.1453-1462, 2008.

HIRDES, A. A reforma psiquiátrica no Brasil: uma (re)visão. Ciência \& Saúde Coletiva, Rio de Janeiro, v. 14, n. 1, p. 297-395, 2009.

JARDIM, V. M. da R. et al. Avaliação da política de saúde mental a partir dos projetos terapêuticos de Centros de Atenção Psicossocial. Revista Texto \& Contexto Enfermagem, Florianópolis, v. 18, n. 2, p. 241-248, 2009.

LOWENKRON, T. Psicoterapia psicanalítica breve. Porto Alegre: Artmed, 2006.

MASHAW, J. Greed, chaos and governance: using public choice do improve public law. London: Yale University Press, 1997.

MENEZELLO, M. D. C. Agências reguladoras e o direito brasileiro. São Paulo: Atlas, 2002.

MORAES, A. de. Agências reguladoras. In: MORAES, A. de (Org.). Agências Reguladoras. São Paulo: Atlas, 2002. p. 13-38. 
NUNES, E.; RIBEIRO, L. M.; PEIXOTO, V. Agências reguladoras no Brasil. In: AVELAR, L.; CINTRA, A. O. (Org.). Sistema político brasileiro: uma introdução. Rio de Janeiro-São Paulo: Konrad Adenauer/Unesp, 2007. p. 183-206.

PELTZMAN, S. A teoria econômica da regulação depois de uma década de desregulação. In: MATTOS, P. (Coord.). Regulação econômica e democracia: o debate norte-americano. São Paulo: Editora 34, 2004. p. 81-130.

POSNER, R. A. Teorias da regulação econômica. In: MATTOS, P. (Coord.). Regulação econômica e democracia: o debate norte-americano. São Paulo: Editora 34, 2004. p. 49-8o.

SATO, F. R. L. A teoria da agência no setor da saúde: o caso do relacionamento da Agência Nacional de Saúde Suplementar com as operadoras de planos de assistência supletiva no Brasil. RAP, Rio de Janeiro, v. 41, n. 1, p. 49-62, 2007.
SUIYAMA, R. C. B.; ROLIM, M. A.; COLVERO, L. de A. Serviços residenciais terapêuticos em saúde mental: uma proposta que busca resgatar a subjetividade dos sujeitos? Saúde e Sociedade, São Paulo, v. 16, n. 3, p.102-110, 2007.

VENTURA, C. A. A. As agências reguladoras e seu papel na reestruturação do setor de telecomunicações: um estudo comparado da Agência Nacional de Telecomunicações (Anatel) - Brasil e da Federal Communications Comission (FCC) - EUA. 2004. Tese (Doutorado em Administração) - Faculdade de Economia e Administração da Universidade de São Paulo, São Paulo.

WALD, A.; MORAES, L. R. Agências reguladoras. Revista de Informação Legislativa, Brasília, v. 36, n. 141, p. 143-171, 1999. 